\title{
Moderate epistemic expressivism
}

\author{
Kristoffer Ahlstrom-Vij
}

Published online: 27 September 2011

(C) Springer Science+Business Media B.V. 2011

\begin{abstract}
The present paper argues that there are at least two equally plausible yet mutually incompatible answers to the question of what is of non-instrumental epistemic value. The hypothesis invoked to explain how this can be so-moderate epistemic expressivism - holds that (a) claims about epistemic value express nothing but commitments to particular goals of inquiry, and (b) there are at least two viable conceptions of those goals. It is shown that such expressivism survives recent arguments against a more radical form of epistemic expressivism, as well as two further arguments, framed in terms of the two most promising attempts to ground claims about epistemic value in something other than commitments to particular conceptions of inquiry. While this does not establish that moderate epistemic expressivism is true, its ability to explain a significant but puzzling axiological datum, as well as withstand strong counterarguments, makes clear that it is a theory to be reckoned with.
\end{abstract}

Keywords Epistemic value $\cdot$ Expressivism - Epistemology

What is it for something to be of epistemic value? One straightforward answer invokes the goals of inquiry or cognition. The idea is that the goals of inquiry not only determine what constitutes inquiry in the first place (i.e., something that does not constitute a pursuit of the relevant goals is not inquiry), but also what states, processes, practices, and so on, are epistemically valuable and, as such, make for successful inquiry. More specifically, consider the following argument schema:

K. Ahlstrom-Vij (ه)

Department of Philosophy, University of Copenhagen, Njalsgade 80, 2300 Copenhagen, Denmark e-mail: ahlstrom@hum.ku.dk 
(1) If something is a goal of inquiry, then it is of non-instrumental epistemic value.

(2) $G$ is a goal of inquiry.

(3) Hence, $G$ is of non-instrumental epistemic value.

For example, if true belief is a goal of inquiry, then true belief is of non-instrumental epistemic value and everything that is conducive to true belief is of instrumental epistemic value in virtue of being conducive to the attainment of a goal of inquiry. That, moreover, is how the schema is usually fleshed out. ${ }^{1}$ For ease of reference, let us refer to any philosopher who takes true belief to be non-instrumentally valuable as a veritist. ${ }^{2}$ Setting aside the questions of whether (a) true belief is the only goal of inquiry, and (b) the goal is to be restricted to truths that are in some relevant sense significant, why accept the claim that true belief is a goal of inquiry? William Alston finds himself at a loss for words:

I don't know how to prove that the acquisition, retention, and use of true beliefs about matters that are of interest and/or importance is the most basic and most central goal of cognition. I don't know anything that is more obvious from which it could be derived (Alston 2005, p. 30; emphasis in original).

Many epistemologists side with Alston here. ${ }^{3}$ However, there are epistemologists who do not consider obvious what Alston does. For example, Richard Feldman denies that true belief is a goal of inquiry, for reasons to be discussed in the next section. The goal of inquiry, he maintains, is to fulfill one's epistemic obligations by believing in accordance with one's evidence, where true or reliably formed belief is neither necessary nor sufficient for believing thus. In fact, as will become clear in a moment, considering his view in detail will tell us something important about the possible answers one can give to the very question we started out with, i.e., "What is it for something to be of epistemic value?"

\section{Evidentialism and epistemic value}

According to Feldman (2002), "epistemological success amounts to having justified cognitive attitudes," which, in turn, "amounts to following one's evidence" (p. 382). On one understanding of what it is to have evidence, something is evidence for something else if and only if the former is as reliable indicator of the latter (Goldman 2011). That, however, is not how Feldman understands evidence, the primary reason being that he wants it to be possible for someone in an evil-demon scenario to be justified (and, consequently, also have evidence), despite being subject to massively misleading experiences (Feldman and Conee 1985). In an evildemon scenario, whatever evidence a subject has in virtue of undergoing certain

\footnotetext{
${ }^{1}$ See, e.g., Alston (2005, p. 30), Haack (1993, p. 199), and BonJour (1985, pp. 83-84) for three representative statements, and David (2001) for further references.

2 The term is borrowed from Goldman (1999), who introduces the term 'veritism' to capture the particular brand of epistemology that is concerned with the varieties of processes and practices involved in the production of true belief.

${ }^{3}$ See references in footnote 1 .
} 
experiences, these experiences do not reliably indicate anything about the subject's surrounding. Consequently, if people in evil-demon scenarios are to be able to be justified in their beliefs, justification better not be spelled out in terms of truthindication.

What is it, then, about evidence that justifies belief, if not a relation of truthindication? According to Feldman-here, writing with his long-time partner in evidentialism, Earl Conee-evidence justifies in virtue of a certain coherence relation:

[...] the general idea is that a person has a set of experiences, including perceptual experiences, memorial experiences, and so on. What is justified for the person includes propositions that are part of the best explanation of those experiences available to the person. [...] The best available explanation of one's evidence is a body of propositions about the world and one's place in it that makes best sense of the existence of one's evidence. This notion of making sense of one's evidence can be equally well described as fitting the presence of the evidence into a coherent view of one's situation. So it may be helpful to think of our view as a non-traditional version of coherentism. The coherence that justifies holds among propositions that assert the existence of the non-doxastic states that constitute one's ultimate evidence and propositions that offer an optimal available explanation of the existence of that evidence (Conee and Feldman 2008, p. 98).

In other words, a person's (ultimate) evidence consists in a set of experiences, and sets of propositions are justified in so far as they are part of an explanation of those experiences that coheres with propositions asserting the presence of the experiences in question. Coherence is a complex notion with a long history, and Feldman and Conee, unfortunately, do not spell out the details of the particular notion that they have in mind. However, there is an emerging consensus in the literature that coherence is not truth-conducive, meaning that more coherence does not imply a higher likelihood of truth, even ceteris paribus (Olsson 2005). In fact, such a disconnect between coherence and truth seems to be exactly what Feldman needs in order to accommodate the idea that someone in an evil-demon scenario can be fully justified despite undergoing massively misleading experiences, as long as the propositions believed by the subject in question provide explanations of her experiences that cohere with the presence of those experiences.

This is not to subscribe Feldman to a view on which there is no connection between following one's evidence and believing truly. For one thing, Feldman (2003, pp. 615-616) takes it that a good case can be made for most justified beliefs being true in the actual world. In other words, Feldman's position is compatible with it being the case that, in a world like ours, where experiences tend to provide pretty good information about the external world, basing one's beliefs upon one's evidence is a good means toward forming true belief. Indeed, this might even hold by natural necessity, i.e., in any world with the same natural laws as ours. Crucially, however, Feldman denies that this is something that holds by conceptual necessity. ${ }^{4}$

\footnotetext{
${ }^{4}$ Why are we interested in conceptual rather than natural necessities here? In short, because the latter is of no obvious relevance to axiology. For example, say that we found that, in worlds like ours, inhabited
} 
Again, someone trapped in an evil-demon world, doomed to form nothing but false beliefs about her surroundings, may not only engage in inquiry, according to Feldman, but also engage in successful inquiry - as long as she is basing her beliefs on her evidence. Still, in an evil-demon world, no degree of diligence with respect to basing one's beliefs thus will enable one to form true beliefs about the external world, which is why neither true belief nor reliability is (conceptually) necessary for justification nor, consequently, for epistemic success, according to Feldman, given his identification of the two.

Notice that the veritist may grant this. Nothing said so far goes to show that true belief is the only goal of inquiry. ${ }^{5}$ However, Feldman is not only skeptical about the necessity of truth or truth-conduciveness for epistemic success, but also about its sufficiency. Registering his skepticism about the idea that mere true belief is an epistemic goal, and attaining such belief, consequently, constitutes a form of epistemological success, Feldman poses the following hypothetical:

[...] suppose a person acquires strong evidence against a proposition he has long defended in public. Out of stubbornness, the person retains the old belief. And suppose that, contrary to the new evidence, the old belief is in fact true. If the goal is simply truth, he's achieved the goal and is, in this case at least, an epistemological success. But, as Locke said of a person who does not reason as he ought, "however he sometimes lights on truth, is in the right but by chance; and I know not whether the luckiness of the accident will excuse the irregularity of his proceeding." [...] Setting aside questions of excuses, the idea here seems to be that the person who reasons badly and stumbles onto a truth is not believing as he ought, is not achieving epistemological success (Feldman 2002, p. 378).

Elaborating on a related scenario a couple of sentences further down, Feldman makes it clear that he sides with Locke on this point. To simply achieve true belief is not to achieve any epistemic goal of ours, nor to be any kind of epistemological success:

Imagine a person who makes an unreasonable and unreliable inference that happens to lead to a true belief on a particular occasion. It might be fortunate that he's got this true belief, but I see nothing epistemologically meritorious about it (Feldman 2002, p. 379).

Footnote 4 continued

by creatures with a psychological make-up like ours, basing one's beliefs upon evidence tends to give one a distinct sex appeal. That would be an interesting fact, but it would not render sex appeal a proper object of study for philosophers interested in epistemic axiology. And why is that? I submit, because no oneirrespective of their particular notion of epistemic value-would consider it conceptually necessary that beliefs based on evidence gives you such sex appeal. (For more on the limits of possible conceptions of epistemic value, see Sect. 4.) That said, natural necessities may still be relevant when thinking about the implications of particular axiologies for normative epistemology, as will be argued in Sect. 7.

${ }^{5}$ For example, some epistemic value pluralists take understanding to be non-instrumentally valuable in a manner not reducible to the value of believing truly (see, e.g., Kvanvig 2003 and Pritchard 2010). I have no quarrel with the pluralist for the purposes of this paper. Presently, I am concerned with those who deny that true belief is non-instrumentally valuable; not with those who suggest that true belief is not the sole bearer of such value. 
Clearly, the idea that there is nothing epistemically meritorious about (mere) true belief-that is, that believing truly is neither $a$ goal of inquiry nor one kind of epistemic success-runs contrary to any veritistic account of epistemic value. ${ }^{6}$ Granted, few veritists would deny that there is something epistemically lacking about the person in the scenario Feldman imagines. For example, reliabilists about justification would deny that the person is justified. However, what is at issue here is whether there is anything of epistemic value about his epistemic situation, and that is where the veritist parts company with Feldman. ${ }^{7}$

\section{Epistemic expressivism}

We started out our investigation with the idea that epistemic value is to be understood in terms of the goal of inquiry-i.e., that which not only determines what constitutes inquiry, but also what makes for successful inquiry-and the observation that most epistemologists have identified the latter with the goal of forming true belief. Then we noted that some epistemologists, like Feldman, identify the goal of inquiry not with true belief but with basing one's belief upon sufficient evidence, where basing one's beliefs thus is epistemically valuable independently of whether it is conducive to true belief. In other words, it seems we have stumbled upon two conceptions of what the goal of inquiry is, in turn not only providing two different conceptions of what constitutes inquiry in the first place, but also yielding incompatible verdicts about what is of non-instrumental epistemic value, i.e., believing truly and believing on the basis of sufficient evidence, respectively. So, let us take a step back and ask: Are there any constraints on what one may take the goals of inquiry to be?

According to Hartry Field, the answer is "no":

[There are] no constraints on what one's epistemological goals ought to be: nothing makes it wrong for a person not to care about achieving truth and avoiding falsehood but adopting beliefs that will make him feel good about his cultural origins (Field 2001, pp. 384-385; emphasis in original).

Lynch (2009a, b) has referred to Field's view as a form of epistemic expressivism, and argued that it constitutes an untenable epistemological position. But before considering Lynch's arguments for why this is so in the next section, it will serve us well to first spend some time getting clearer on the relevant kind of expressivism.

In its most general form, expressivism is the idea that normative claims, such as "It's wrong to $\varphi$ ", do not strictly speaking state facts (more on this later), but rather

\footnotetext{
${ }^{6}$ Feldman (in correspondence) confirms that there has been a shift in his views on epistemic value, from his (1988, pp. 247-248), where he accepts that true belief is a goal of inquiry, and simply denies that true belief has anything to do with value, to his (2002), where he (as we have seen) denies that true belief has anything to do with epistemic value by denying that it is a goal of inquiry.

7 Nothing said so far goes to show that no evidentialist about justification can be a veritist. See, e.g., Goldman's (2011) evidentialist reliabilism. The point is simply that there are forms of evidentialism (such as Feldman's) that are incompatible with veritism, because the particular theory of epistemic success that is invoked to explain the value of justification rules out believing truly being a goal of inquiry.
} 
express something like a sentiment (e.g., Ayer 1952), or a commitment to a set of norms on part of the person making the claim in question (Gibbard 1990). The particular kind of epistemic expressivism relevant presently is best spelled out in terms of normative commitments rather than sentiments, and can be summed up in terms of two claims. First:

(A) Claims about epistemic value express nothing but commitments to a particular (set of) goal(s) of inquiry.

Notice that (A) is not formulated directly in terms of values but rather in terms of claims about value. How does this relate to the question we started out with, namely "What is it for something to be of epistemic value?" Here, (A) should be read as making what J. Adam Carter and Matthew Chrisman (2011) have referred to as "the core expressivist maneuver," in that it addresses a question about what values are in terms of what it is to take something to be valuable. This, of course, is the exact maneuver Allan Gibbard (1990) makes when he says that his expressivist analysis of rationality "is not directly of what it is for something to be rational, but of what it is for someone to judge that something is rational" (p. 8; emphasis in original). It is important to note, however, that Gibbard is not simply changing the subject here. Instead, the motivation for this maneuver is that expressivists typically wish to remain anti-realist with respect to the kind of normative facts postulated by the realist. According to the expressivist, to the extent that there are normative factsand the expressivist may grant that there are-they are facts about what we value, rather than some kind of sui generis normative facts. In that respect, we might even say that (A) should be understood as having an implicit addition, namely "... and that is all there is to the metaphysics of epistemic value." As Blackburn (1993) puts the point in relation to moral discourse, expressivism (or quasi-realism, as he calls it) "avoids the view that when we moralize we respond to, and describe, an independent aspect of reality" (p. 157). Rather, when we assert values, we simply voice (Blackburn 1998, p. 50) or express (Gibbard 1990, p. 8) our state of mind. Hence, expressivism.

The idea that value claims express states of mind-e.g., states of mind constituting commitments to particular goals of inquiry, as per (A) — should not be confused with the subjectivist idea that value claims describe states of mind. As Gibbard puts it: "To express a state of mind is not to say that one is in it" (1990, p. 154). To commit to an expressivist analysis of some normative phenomenon is also not to commit to relativism about that phenomenon (or if it is, it is at most to commit to an utterly harmless form of relativism, as we shall see in a moment). For example, Gibbard not only takes normative claims to have "an automatically recommending force" (p. 20), but also maintains that the norm underlying the recommendation in any particular case typically is treated as "valid independently of our own acceptance of it" (p. 166). Blackburn makes a similar claim when he suggests that, as soon as we employ normative terms, we are moralizing, and moralizing simply leaves no room for relativism, despite the fact that moralizing always involves expressing a particular moral stand, or inhabiting "a particular ethical boat," as he puts it: 
To 'see' the truth that wanton cruelty is wrong demands moralizing, stepping back into the boat, or putting back the lens of a sensibility. But once that is done, there is nothing relativistic left to say (Blackburn 1993, p. 178).

At this point, it is interesting to bring in Field's (2009) particular brand of expressivism, since he refers to it as a kind of relativism. Field's idea is that evaluations (or at least epistemic evaluations) are not straightforwardly factual, in that they "involve a free parameter, for a norm of assessment" (p. 251). Moreover, Field claims that any normative statement, consequently, can be explicitly relativized by mentioning the relevant norm. In other words, any instance of

(O) "We ought to $\varphi$ "

can be reformulated as follows:

$\left(\mathrm{O}^{*}\right)$ "We ought to $\varphi$ relative to norm $n . "$

Interestingly, however, Field finds it "highly misleading" to claim that instances of schemata like $(\mathrm{O})$ and $\left(\mathrm{O}^{*}\right)$ say the same thing, or even that they have the same truth-conditions. ${ }^{8}$ He even maintains that it is possible to disagree over normative matters in cases where a proper relativization of the relevant normative claims ends up having the disagreeing parties appeal to distinct norms. ${ }^{9}$ In other words, if Field's expressivism implies any kind of relativism, it is of an utterly harmless kind, when compared to what we may refer to as full-fledged relativism, i.e., the kind of relativism that typically is taken to be problematic exactly on account of the implications that Field denies that his kind of relativism has. ${ }^{10}$ In light of this, it is not clear that Field's expressivist relativism ends up having implications beyond those of standard forms of expressivism, such as those of Blackburn and Gibbardwhich, moreover, makes sense of Field's otherwise highly puzzling claim to the effect that his expressivism is a mere "notational variant" (p. 252) on Gibbard's. In light of this, the relativistic aspect (if any) of Field's theory will receive no further attention here, although Sect. 7 below will consider a close relative of relativism, namely parochialism.

As far as the present investigation is concerned, the main problem with Field's position lies neither in its expressivism nor in its (alleged) relativism, but in the claim that we started out the present section with:

(B) There are no constraints on what one's goal(s) of inquiry can be.

For reasons that will become obvious as we go along, we may refer to the combination of (A) and (B) as radical epistemic expressivism. Remember, the goals of inquiry not only determine what constitutes inquiry in the first place, but also what is epistemically valuable and, as such, makes for successful inquiry. So, if there are no constraints on what one's goals of inquiry can be (as per B), and claims about epistemic value express nothing but commitments to a particular set of such

\footnotetext{
8 See Field (2009, pp. 276-278).

9 See Field (2009, p. 275).

10 See, e.g., Boghossian (2006, Chap. 6), who rejects relativism exactly on account of the problems raised by the relativist's insistence on the equivalence of instances of schemata like $(\mathrm{O})$ and $\left(\mathrm{O}^{*}\right)$.
} 
goals (as per A), then there are also no constraints on what one may take to be of epistemic value. Maybe most of us do not think of inquiry in terms of whatever flatters our cultural origins; Field's point is simply that there is nothing that would stop us from doing so.

\section{Against radical epistemic expressivism}

Lynch provides two arguments against radical epistemic expressivism that are meant to block the above inference to the claim that there are no constrains on what one may take to be of epistemic value. First, consider what we may refer to as the no inquiry argument, which is directed against (B). The idea is that someone who is forming belief in a manner that involves no commitment to the idea that propositions are to be embraced if and only if they are true is not engaging in inquiry. Lynch (2009a) makes this point in relation to a hypothetical example including someone-let us call him Steve-who is committed to the goal of "accepting" all and only propositions that flatter his cultural origin. Is Steve, thereby, engaging in inquiry? Lynch suggests that the answer has to be "no," since the practice Steve is engaging in does not involve a commitment to the idea that propositions are to be embraced if and only if they are true. Whatever practice Steve is involved in, it is not inquiry.

When applied to Steve, this line of reasoning is highly convincing. As such, it also goes to refute (B), by suggesting that there are some constraints on what one's goals of inquiry can be. But does the point in question generalize to any practice that does not involve a commitment to the idea that propositions are to be embraced if and only if they are true, including a practice that involves (nothing but) a commitment to the idea that propositions are to be embraced if and only if they are supported by sufficient evidence, as Feldman would have it? It is not clear that it does. To see why, consider two ways in which the relevant point about possible goals of inquiry could be pushed. On the one hand, it could be maintained that the norm according to which we should believe something if and only if it is true attaches to the relevant notion of inquiry by conceptual necessity. In that case, the dispute seems to boil down to one about meanings, and the veritist would have to resort to either suggesting that Feldman is conceptually confused-a claim that is highly implausible in light of him being one of contemporary epistemology's most prominent contributors-or granting that the evidentialist is using a different yet equally legitimate notion of inquiry and its goals.

On the other hand, Lynch makes it clear that this is not how he views matters:

[...] it isn't at all obvious that the above arguments need to be understood as being about the meanings of "inquiry" or "belief" or "language". As we noted earlier, (TN) [i.e., the idea that it is prima facie correct to believe $<p>$ if and only if $\langle\mathrm{p}\rangle$ is true] and what follows from it needn't be thought of as conceptual truths. One could take such points to be about inquiry and belief rather than "inquiry" and "belief". Cooking aims to produce food; comedy aims to produce laughter. Likewise, one might think, inquiry aims to produce 
true beliefs. It is a fact about such practices that they cannot be separated from their aims; their aims are partly constitutive of them (Lynch 2009b, pp. 90-91).

In other words, rather than pertaining to conceptual necessities, the relevant truths about the goals of inquiry may, as Lynch suggests, be truths of constitution. This gets not so much to (B) as to (A), i.e., the idea that claims about epistemic value express nothing but commitments to a particular set of goals of inquiry. However, at this point, the argument starts to look question begging, if directed against the evidentialist. More specifically, the argument against counting above evidentialist practice as a form of inquiry would, under this construal, require a premise to the effect that inquiry just is (insert table-thumping here) the pursuit of truth, which is exactly the claim that the evidentialist contests. Clearly, the evidentialist has no reason to grant the veritist that premise. ${ }^{11}$

Lynch seems to admit this point in noting that he "cannot give a non-circular justification of my belief that it is valuable to engage in inquiry [as construed by the veritist]; for in answering the question I am already committed to the value of the very practice in question" (2009a, p. 239). Moreover, he grants that, far-fetched examples like the one with Steve aside, it seems at least prima facie reasonable to say that someone may engage in inquiry in a context where the latter is spelled out in terms of the goal of having a coherent belief system, or having epistemically rational or justified beliefs. At this point, however, the second argument enters, an argument that we may refer to as the presupposition argument. Lynch writes:

No doubt, people can and do have such goals in pursuing inquiry. The question is whether [...] we can conceive of someone who has distinct epistemic goals that don't include the goal of having true belief. Of course, the typical way of understanding inquiry does require that it have only one goal: truth [...]. The thought here is that the value of achieving, e.g. a coherent belief system lies in the fact that doing so is instrumental to believing what is true and not believing the false. [...] If we didn't think this, it seems unlikely that we would care whether our beliefs were coherent. But of course if this is how we see the matter, having the goal of coherence or justification presupposes having the goal of true belief (Lynch 2009b, p. 89).

The problem is, of course, that this is not how the evidentialist, at least of Feldman's stripe, sees the matter. As we saw above, he denies exactly that the value of justification, i.e., of basing your beliefs upon sufficient evidence, is parasitic upon the value of believing truly. Suggesting that the evidentialist's axiology presupposes such a relationship would be to misconstrue his position, at best, and to beg the question, at worst. As such, we may conclude that neither the no inquiry nor the presupposition argument establishes that Feldman's evidentialist take on epistemic value and the goal of inquiry is not completely viable.

\footnotetext{
11 The same point can be made, mutatis mutandis, against any analogous attempt in terms of there being a constitutive or conceptual connection between truth and belief, on account of the former being the norm of the latter, and inquiry being the practice of belief-formation. See, e.g., Lynch (2009a).
} 


\section{Moderate epistemic expressivism}

To recapitulate, Field is wrong in suggesting that there are no constraints whatsoever on what one can take the goals of inquiry to be, as made clear by the failure of (B). This blocks the inference from (A) and (B) to the idea that there also are no constraints on what one may take to be of epistemic value. However, Lynch is wrong in assuming that this leaves veritism as the sole contender. Again, the goals of inquiry not only determine what constitutes inquiry in the first place, but also what is of non-instrumental value and, as such, makes for successful inquiry. While Lynch's arguments show that there are some constraints on what one may take these goals to be, the plausibility of Feldman's evidentialist take on epistemic value suggests that the following holds:

(B*) There are at least two viable conceptions of the goal(s) of inquiry.

Combining (A) with $\left(\mathrm{B}^{*}\right)$ we get what we may refer to as a moderate epistemic expressivism. The two conceptions that have concerned us here are, of course, that of the veritist and that of the evidentialist. Moreover, the two conceptions are incompatible, in that the evidentialist denies the veritist's claim that true belief is a goal of inquiry and, as such, of non-instrumental epistemic value, while the veritist typically takes the value of basing one's beliefs upon sufficient evidence to be merely instrumental. ${ }^{12}$ But what is it for the two conceptions to both be viable? To say that a conception is viable is not to endorse it-again, the two conceptions we have been concerned with above are incompatible, so clearly one cannot endorse both. More specifically, while we deem viable whatever particular conception we endorse, we do not endorse all conceptions we deem viable. To deem two (or more) conceptions viable, in accordance with $\left(\mathrm{B}^{*}\right)$, is in effect to declare an axiological modus vivendi between several conceptions of inquiry, all of which one understands and perhaps even is willing to grant some degree of theoretical integrity, but only one of which one endorses.

How is $\left(\mathrm{B}^{*}\right)$ different form epistemic value pluralism, i.e., the idea that there is a plurality of epistemic goals ? $^{13}$ The difference is that $\left(\mathrm{B}^{*}\right)$, unlike epistemic value pluralism, is not a claim about how many goals of inquiry there are, but a metaclaim about there being at least two viable conceptions of such goals. As such, $\left(\mathrm{B}^{*}\right)$ carries no commitment as to how many goals those conceptions postulate. None of this rules out, of course, that someone who is a value pluralist and, thereby, takes there to be a plurality of epistemic goals also might commit herself to the further and logically independent meta-idea that there are several viable conceptions of such goals, in accordance with $\left(\mathrm{B}^{*}\right)$. However, nothing about her value pluralism commits her to $\left(\mathrm{B}^{*}\right)$. She would in no way compromise her value pluralism, were she to claim that there is one and only one viable conception of the goals of inquiry,

\footnotetext{
12 As such, a veritist may, of course, disagree with Feldman while, at the same time, being an epistemic value pluralist in virtue of postulating some other non-instrumental epistemic value in addition to that of true belief.

13 See, e.g., DePaul (1993) and Kvanvig (2005) for two defenses of epistemic value pluralism.
} 
namely hers, and that this conception postulates a particular plurality of epistemic goals.

But does the converse hold, i.e., does ( $\left.\mathrm{B}^{*}\right)$ imply any kind of value pluralism? Someone may reason as follows: If there are at least two viable conceptions of the goals of inquiry, and each conception has to postulate at least one such goal for endorsement, then $\left(\mathrm{B}^{*}\right)$ implies that there is a plurality of epistemic goals, albeit spread out over several conceptions. This, however, looks nothing at all like the kind of plurality that the typical epistemic value pluralist is after. Take one of the most popular considerations in favor of value pluralism, i.e., the swamping problem. ${ }^{14}$ By way of illustration, consider reliabilism, i.e., the view that knowledge is reliably formed true belief. If we are reliabilists and truth monists-i.e., if we believe that true belief is the only epistemic goal-it is going to be hard to explain why we value knowledge more than true belief. After all, if truth is what we are really after, as far as inquiry is concerned, why value reliability in addition to true belief? As Kvanvig (2003) puts the point, the presence of truth "swamps" the epistemic value of reliability. Now, if we follow the value pluralist in accepting that this indeed is a problem, then it should be clear that it will do no good whatsoever to simply postulate an additional conception of the goals of inquiry-say, one on which justification is a goal independent of that of true belief - in addition to the one we already endorse. What we would need to do is revise our current conception by endorsing an additional goal of inquiry, such as the goal of justification. After all, only by postulating plurality within our own conception can we actually aggregate the relevant values in such a way as to account for the relevant surplus value.

Say that someone accepted $\left(\mathrm{B}^{*}\right)$. Why should that someone also accept (A), i.e., the expressivist idea that claims about epistemic value express nothing but commitments to a particular (set of) goal(s) of inquiry? For one thing, (A) provides an anti-realist metaphysics for epistemically normative facts, as made clear in Sect. 2. In so far as ontological parsimony is a good thing in axiology, this provides a reason (whether or not it is a decisive reason) for accepting (A). More relevant presently, however, is that the combination of $(\mathrm{A})$ and $\left(\mathrm{B}^{*}\right)$ provides a promising and - in virtue of (A) - ontologically lean account of how it can be that there are (at least) two equally viable yet mutually incompatible answers that can be given to the question of what is of epistemic value - a prima facie puzzling axiological datum. The account follows Field in suggesting that epistemic value is to be explained in terms of what is expressed by claims about epistemic value (in accordance with the core expressivist maneuver), and that what is expressed is nothing but commitments to certain goals of inquiry, as per (A). That, the view holds, is all there is to the ontology of epistemic values: facts about what we take to be valuable in the domain of inquiry. However, in virtue of $\left(\mathrm{B}^{*}\right)$, the account also differs from Field's by being compatible with there being some constraints on what one may take the goals of inquiry to be, in accordance with Lynch's arguments against (B). This is what renders the resulting kind of expressivism moderate, compared to Field's expressivism.

\footnotetext{
$\overline{14}$ See, e.g., Kvanvig (2003), Zagzebski (2003), Sosa (2003), and Swinburne (1999).
} 
The virtues of moderate epistemic expressivism may be brought out more clearly by spelling out how such expressivism would account for the ways in which Lynch's arguments fall short of discrediting anything beyond radical epistemic expressivism, as per what was argued above. On this score, let us start by considering in virtue of what aforementioned constraints on what one may take the goals of inquiry to be hold. I submit that they hold in virtue of certain conceptual facts about possible notions of inquiry. In fact, taking the relevant facts to be conceptual makes sense of how Lynch's appeals to what constitutes inquiry become nothing short of question-begging when applied to Feldman's perfectly legitimate conception of evidentialist inquiry. After all, both the veritist and the evidentialist can understand each other's axiological frameworks, where understanding something, of course, is distinct from endorsing it. More than that, if what has been argued so far is on the right track, both the veritist and the evidentialist should appreciate the integrity of each other's frameworks, even if neither is (or, for that matter, should be) tempted to give up their own. In other words, being committed to some particular conception of the goal(s) of inquiry in one's expressions of epistemic value does not rule out being able to conceive of other ways of understanding inquiry, whether or not such reflections lead one to reconsider one's commitments.

Why take the relevant conceptual facts to be facts specifically about possible notions of inquiry? Because it accounts well for the fact that our conceptual abilities to conceive of alternative axiological frameworks also have their limits. In particular, it makes sense of the fact that, if Field would indeed be prepared to describe Steve's project as one of inquiry, he (i.e., Field) would be best characterized as doing either of two things. On a charitable reading, he would be characterized as working with a conceptual framework that (unlike Feldman's) is sufficiently foreign from our own to be disregarded. On a less charitable reading, he would simply be saying something bordering on the incomprehensible, on account of teetering on the limits of possible conceptions of inquiry, as defined by said conceptual facts. It might be hard to spell out exactly what these conceptual facts are, of course. But it suffices for the purpose of deciding between (B) and ( $\left.\mathrm{B}^{*}\right)$ to note that, whatever the relevant facts are, they are at the very least such as to give rise to some constraints, where those constraints leave room for several, incompatible notions of inquiry, while still ruling out the practice Steve is engaging in as an instance of inquiry. ${ }^{15}$ Moreover, since Lynch's argument do not refute (B*), nor bring any convincing considerations to bear on (A), we may conclude that, while Lynch has successfully rebutted radical epistemic expressivism, he has said nothing to discredit moderate epistemic expressivism.

\footnotetext{
15 Are these conceptual facts normative facts? Not exactly. As suggested above, the relevant facts put certain constraints on what one may take the goals of inquiry to be. Since what one takes the goals of inquiry to be determines what one takes to be epistemically valuable, the relevant conceptual facts are not themselves normative facts but rather constraints on what epistemically normative facts there can be. Notice, however, that all of this "fact talk" is consistent with the anti-realism of expressivism, since such anti-realism is perfectly compatible both with there being conceptual facts, and (as argued above) with there being normative facts in the minimal sense of facts about what we take to be valuable.
} 
To sum up, moderate epistemic expressivism provides a promising account of how it can be that there are (at least) two equally viable yet mutually incompatible answers that can be given to the question of what is of epistemic value-i.e., that of the veritist and that of the evidentialist-without falling prey to Lynch's arguments against more radical forms of epistemic expressivism. This is not to suggest that the veritist or the evidentialist should stop valuing their respective goods noninstrumentally. The point is simply that neither the veritist nor the evidentialist can impose their respective notion of value on the other, as long as the relevant values are grounded in nothing but different conceptions of the goals of inquiry. This gets to (A), and the question whether claims about epistemic value really cannot be grounded in anything extra-conceptual. Again, (A) was introduced above to account for a puzzling axiological datum in an ontologically lean manner. If a case can be made that claims about epistemic value can be grounded in something extraconceptual, we would have reason to reject (A), independently of its ability to account for that datum.

In light of this, the following two sections will consider what I take to be the two most promising arguments-one on part of the veritist (Sect. 5), and one on part of the evidentialist (Sect. 6) - for grounding at least some claims about epistemic value in something other than conceptions of the goals of inquiry. If either argument is successful, it would serve to discredit (A) as a central element in the epistemic expressivist's anti-realist attempt to restrict the domain of facts about epistemic values to facts about people expressing commitments to particular notions of inquiry. More specifically, it would show that, for at least some epistemic value claims, there are facts of the matter as to whether we should value the relevant goods non-instrumentally, irrespective of what happens to be our particular conception of the goals of inquiry. Let us start by considering the veritist's attempt to make a case to this effect.

\section{Truth and self-knowledge}

According to Lynch (2004), we care about having true beliefs, where "caring for something entails that we treat it as [an] end" (p. 119). Differently put, we take true belief to be of non-instrumental value. But what reasons do we-as in: all of us, irrespective of our particular notions of the goals of inquiry-have for valuing truth? Lynch provides a series if arguments meant to answer this question. I will focus on the argument he refers to as the argument from self-knowledge. ${ }^{16}$ Let us consider Lynch's formulation of the argument, before turning to his definitions of the notions invoked (and I quote):

(4) Self-respect and authenticity require a sense of self.

(5) Because it is required for self-respect and authenticity, which are part of happiness, having a sense of self is an important part of happiness.

\footnotetext{
${ }^{16}$ Lynch (2004) provides six arguments in total. However, three of these pertain to instrumental values (pp. 174-177), and the fourth and fifth fail for the same reason as the sixth does (see footnote 17), which is the argument to be discussed here.
} 
(6) Having a sense of self means having true beliefs about what you care about.

(7) Therefore, having some true beliefs - about what you care about-is also part of happiness, other things being equal (Lynch 2004, p. 127).

"If we grant," Lynch continues, "that whatever is part of happiness is worth caring about for its own sake, from these premises we can deduce that the truth about what you care about is itself worth caring about for its own sake" (p. 127). In other words, Lynch wants to infer the conclusion

(8) the truth about what you care about is worth caring about for its own sake,

from (4) to (7), together with the following additional premise:

(AP) If $x$ is part of some $y$ (e.g., happiness) that is worth caring about for its own sake, then $x$ is worth caring about for its own sake.

Let us consider each premise in turn. To have self-respect, as Lynch understands it, is to have a sense of your own value (p. 124), while authenticity is to identify with the desires that guide your actions (p. 125). To have a sense of self is to have true beliefs about what you care about, as per premise (6). Since it is, arguably, impossible to either have a sense of your own value, or to identify with the desires that guide your action, without having true beliefs about what you care about, selfrespect and authenticity require a sense of self. Hence, premise (4).

Premise (5) maintains that self-respect and authenticity are parts of happiness. What does it mean to be a part of something here? Lynch explains:

Being a part of something good is crucially different from being a means to it.

A means to an end is ipso facto different from the end itself. A necessary part of something, on the other hand, helps make the whole of which it is a part the thing that it is. Change or destroy the part and you change or destroy the whole (Lynch 2004, p. 128; emphasis in original).

In other words, for $x$ to be a part of $y$ is for $x$ to be a necessary part of $y$, such that the absence of $x$ implies the absence of $y$. Interpreting premise (5) accordingly, and granting premise (6) - i.e., that having a sense of self means having true beliefs about what you care about-it follows that having true beliefs about what you care about is a necessary part of happiness. If that is how we are to understand what it is to be a part of something, (7) can be reformulated as follows:

(7*) Having true beliefs about what you care about is a necessary part of happiness, other things being equal.

It might seem strange to talk about something being a necessary part of something, other things being equal. After all, to be a necessary part of something is to be a part of something by necessity, i.e., irrespective of whether other things are equal. However, what Lynch means to indicate is that the value in question is pro tanto, in that it may be overruled by other considerations and, hence, is not an all-thingsconsidered good (pp. 46-51). In other words, the conclusion that we are to draw from Lynch's argument is the following: 
(8*) The truth about what you care about is worth caring about for its own sake, in the sense that having the true beliefs in question is a pro tanto good in itself.

If Lynch's argument succeeds in establishing $\left(8^{*}\right)$, then we have found an argument to the effect that at least some true beliefs are (pro tanto) valuable in themselves, irrespective of what happens to be one's favored conception of the goals of inquiry. This would count against (A), i.e., the idea that claims about epistemic value simply express commitments to some (set of) goal(s) of inquiry, at least when understood in the context of the epistemic expressivist's claim that there are no facts about epistemic values beyond whatever facts there are about people expressing such commitments.

There is a problem with Lynch's argument, however, and the problem is (AP). We may see more clearly what the problem is by reformulating (AP) in light of Lynch's definition of what it is for something to be a part of something as follows:

(AP*) If $x$ is a necessary part of some $y$ (e.g., happiness) that is worth caring about for its own sake-i.e., if $x$ is such that its absence implies the absence of that of which it is a part-then $x$ is worth caring about for its own sake.

Clearly, (AP*) is not true. It does not follow from $x$ being a necessary part of $y$, that, if $y$ is worth caring about for its own sake, then the same goes for $x$. By way of illustration, assume that true belief is worth caring about for its own sake. If (AP*) were true, it would follow that mere belief, being a necessary part of true belief, would be worth caring about for its own sake. This clearly cannot be right, even if we qualify the good involved as being a mere pro tanto good. Hence, (AP*) cannot be true, and if (AP*) is not true, then we do not get the conclusion that Lynch wants to draw from (4) to $(7)$, namely $(8 *){ }^{17}$

Two things need to be noted about what should not be inferred from the failure of Lynch's argument. First, while it failed to establish that some true beliefs are noninstrumentally valuable (pro tanto or otherwise) irrespective of your particular conception of the goals of inquiry, and thereby also failed to discredit (A), nothing said so far rules out the possibility that having certain true beliefs (e.g., about what you care about) is under many circumstances conducive to leading a flourishing life. However, that at most establishes that some instances of true belief are instrumentally valuable. As such, it provides no reason for evidentialists or other non-veritists who do not already value (any) true belief non-instrumentally to start doing so.

\footnotetext{
17 The same goes for Lynch's (2004) structurally identical arguments about intellectual integrity (p. 136) and sincerity (p. 157). Notice also that we can run the same argument even if we interpret (AP*) in terms of supervenience. After all, it does not follow from $y$ being valuable in itself that, if $x$ is part of the supervenience base of $y$, then $x$ is also valuable in itself. By way of illustration, assume that being a person is valuable in itself. Assume, furthermore, that facts about person-hood supervene on neurological facts, and that I am the person I am in virtue of instantiating the particular neurological facts $N_{1}-N_{850}$. Then, take any neurological fact in this series, say, $N_{46}$. Is instantiating $N_{46}$ valuable in itself? It is notdespite it being part of the supervenience base of something that (by hypothesis) is valuable in itself.
} 
Second, the failure of the above argument does not go to show that those who already value true belief non-instrumentally should stop doing so. However, in want of an account of the non-instrumental value of true belief that appeals to something beyond particular conceptions of the goals of inquiry, the veritist must accept the fact that she can provide no reasons for those who do not already share the relevant conception to start valuing true belief non-instrumentally. The next section considers the matter from the other side, by investigating the possibility that the evidentialist can provide an analogue of the argument that Lynch could not provide for the veritist, i.e., an argument to the effect that we-contrary to (A)—should value basing our beliefs upon sufficient evidence non-instrumentally, irrespective of what happens to be our particular notion of the goals of inquiry.

\section{The ethics of belief and the value of evidence}

In "The Ethics of Belief" (1866), Clifford famously argues that "[i]t is wrong, always, everywhere, and for any one to believe anything upon insufficient evidence" (p. 346). For Clifford, this follows from a more fundamental, diachronic duty of inquiry, i.e., "the universal duty of questioning all that we believe" (p. 344). In questioning our beliefs, we attempt to find out whether or not they are based on sufficient evidence. If they are, we may continue holding them, knowing that they have been "fairly earned by investigation" (ibid.). If they are not, "we have to begin again at the beginning, and try to learn what the thing [under investigation] is and how it is to be dealt with-if indeed anything can be learnt about it" (ibid.). It is as a fruit of such "scrupulous care and self-control" (p. 347) that we, on Clifford's picture, should understand the value of believing upon sufficient evidence. As suggested by the case of belief suspension in situations where it turns out that nothing can be learnt about the object under investigation, believing upon sufficient evidence may not be the only way of satisfying the duty of inquiry, but probably the only happy way to do so.

What is relevant for our purposes is that, if Clifford is right, even those who do not happen to share Feldman's evidentialist conception of the goal of inquiry ought to value having their beliefs be based upon sufficient evidence non-instrumentally. To see why, consider the fact that Clifford, unlike the great majority of contemporary epistemologists, seems to take our epistemic duties to be a mere subset of our ethical duties. ${ }^{18}$ With this in mind, consider the following argument:

(9) We have a duty to only believe upon sufficient evidence, and the duty is an ethical one.

(10) To believe propositions upon sufficient evidence is to satisfy the duty to only believe upon sufficient evidence with respect to the relevant propositions.

(11) Satisfying an ethical duty is non-instrumentally valuable.

(12) Hence, to believe upon sufficient evidence is non-instrumentally valuable.

(13) The relevant ethical duty applies universally.

18 See Haack (2001) for a convincing set of arguments to this effect. 
(14) To believe upon sufficient evidence is non-instrumentally valuable for everyone.

Premise (9) captures the duty Clifford infers from the duty of inquiry, and identifies it as an ethical one. Premise (10) corresponds to aforementioned observation about how we may satisfy the duty in question by believing upon sufficient evidence. Premise (11) amounts to an assumption that will be granted for the sake of the argument, i.e., that satisfying our ethical duties-whatever they are-is noninstrumentally valuable. Moreover, if all epistemic duties are ethical duties, the same applies to the former, as per premise (12). Assuming that the relevant ethical duties apply universally, as per premise (13), believing upon sufficient evidence is non-instrumentally valuable not only for those who share the evidentialist conception of epistemic success, but for everyone, as per (14).

While this is a valid argument, premise (9) is highly implausible. In so far as we have a duty to only believe upon sufficient evidence, that duty is an epistemic rather than a moral one, as evidenced by the fact that we can evaluate subjects in terms of this norm even in cases where the relevant conduct is morally inconsequential. In light of this, it should come as no surprise that contemporary epistemologists sympathetic to the idea of an ethic of belief tend to embrace a distinction between ethical and epistemic duties. For example, in spelling out his evidentialist take on Clifford's position, Feldman (1988, pp. 236-237) makes it clear that beliefs with morally bad consequences can still be epistemically obligatory. Similarly, when claiming that every person is required to try her best to bring it about that, for every proposition considered, she accepts the proposition only if it is true, Chisholm (1977, p. 14) specifies the requirement as a purely intellectual requirement. ${ }^{19}$ In other words, the main modern defenders of Clifford's project construe it not so much as an ethics of belief as an epistemology of belief formation. ${ }^{20}$

In so doing, however, the neo-Cliffordians also surrender the one aspect of Clifford's theory that would provide them with a way to convince the veritist of the non-instrumental value of basing one's belief upon sufficient evidence. As argument (9)-(14) makes clear, the reason Clifford's account was promising on this score was exactly because it took our duty to base our beliefs thus to be an ethical duty-a fact that, given the wide scope and non-instrumental nature of our ethical duties, would provide a lever for extending the normative force of the evidentialist's emphasis on the value of evidence beyond those who happen to share their conception of the goal of inquiry, contrary to what we would expect if (A) holds. In so far as this ambition is not present in modern defenders of an ethics of belief, they may, thereby, be constructing far more plausible accounts of the relevant evidentialist norms than Clifford did, albeit at the expense of providing little by way of arguments for

\footnotetext{
19 Chisholm does at times write as if epistemic duties are a mere subspecies of ethical duties, e.g., in his (1991, p. 119). However, when spelled out, the claim turns out to be that ethical duties are duties that are not overridden by any other requirement, and non-overridden epistemic duties (like any non-overridden duties), hence, are ethical duties (see pp. 127-128). This only goes to show that some epistemic duties are ethical duties, not that all are, nor consequently that the former are a mere subspecies of the latter.

${ }^{20}$ Wolterstorff (2005) is a possible exception.
} 
discrediting (A), or convincing the veritist of the non-instrumental value of believing upon the basis of sufficient evidence.

\section{Conclusion: parochialism or browbeating?}

Let us conclude by returning to the question we started out with: What is it for something to be of epistemic value? Restricting our attention to non-instrumental epistemic value, we have seen that there are at least two viable yet mutually incompatible answers one may give to this question, namely to believe truly and to base one's belief upon sufficient evidence, respectively. The hypothesis invoked to explain how this can be so held that (a) claims about epistemic value express nothing but commitments to particular goals of inquiry, and (b) there are at least two viable conceptions of those goals. Above, this hypothesis was dubbed moderate epistemic expressivism, and distinguished from a more radical (and implausible) form of epistemic expressivism, which denied that there are any constraints whatsoever on what one may take the goals of inquiry to be. Having shown that moderate epistemic expressivism survives the arguments leveraged against such radical epistemic expressivism, we then considered two further, and ultimately unsuccessful, arguments against the former, that attempted to demonstrate that certain epistemic value claims may be grounded in something other than commitments to particular conceptions of the goal(s) of inquiry.

Now, it cannot be denied that, from the standpoint of anyone with fairly firm axiological commitments (the present author being one such person), there is something slightly unsettling about what has been argued, and I would like to end by addressing this feeling. Notice, first, that the relevant feeling is predicted by the present expressivist framework. Given the "automatically recommending force" (p. 20), as Gibbard (1990) called it, of our normative judgments, and the fact that we tend to treat the norm underlying the recommendation in any particular case as "valid independently of our own acceptance of it" (p. 166), finding that we cannot convince others to accept our norms is bound to be frustrating. At the same time, accepting what has been argued above does not commit us to any full-fledged kind of relativism. Even setting aside any independent worries that we might have about such relativism, the fact remains that it simply does not fit our practices of evaluation very well, as argued at length by expressivists like Gibbard and Blackburn. This is not to deny that we sometimes come across people who do not share our commitments. Sometimes we do, and when we do, we try to reason with them, and hope that they share enough of our sensibilities to eventually come around to seeing things the way we do. ${ }^{21}$

When they do not, we may try to identify some non-question begging reason for thinking that (at least) some of those who do not share our commitments are mistaken. This is, in effect, the kind of reasons we were searching for in Sects. 3-6 above-reasons for thinking that either the veritist or the evidentialist had made a

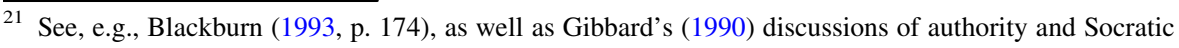
influence.
} 
mistake about epistemic value-albeit in vain. While what has been argued does not establish that such reasons cannot be found, it provides grounds for doubting that any arguments establishing such reasons are forthcoming. This, in turn, raises a question: In the absence of such reasons, what are we to do? One option is to embrace what Gibbard (1990) refers to as parochialism. When opting for parochialism, we narrow somewhat the claim to universal acceptance that we in the standard case attach to the norms we express through our normative judgments. It is not necessary that we go relativist, and claim that some set of normative statements are true for us, and another set is true for those who do not share our normative commitments. We could, but that is optional. The parochial alternative is that we simply do not assume that our normative judgments will have any recommending force for those who happen not to share our normative commitments, and leave the question of exactly what to think about such foreign axiologies unanswered, in so far as we raise it at all.

This might sound terribly unsatisfying. But consider the options: While fullfledged relativism does not do a good job in accounting for our evaluative practices, and we still have not found any arguments suggesting that those who do not share our normative commitments are normatively mistaken, parochialism constitutes an attractive alternative to what seems the only other option: browbeating. More than that, the costs of parochialism must be considered in the context of its implications for epistemic evaluation. Here, it is particularly important to note that, given Feldman's acknowledgement of the contingent-if not naturally necessaryconnection between basing your belief on evidence and believing truly, there is likely to be a significant overlap between the normative judgments made by evidentialists and veritists. Granted, there will be some divergences (e.g., in the case of mere true belief, as discussed in Sect. 1). In addition, the two will invoke incompatible axiological explanations even in cases where they agree that something is epistemically good. But the fact remains that one of the best strategies for forming true belief in a world like ours is to base one's beliefs on evidence. Consequently, what is taken to be of epistemic value is going to be largely coextensive for the veritist and the evidentialist, despite underlying axiological differences - differences that, thereby, do not necessarily have to get in the way of a fairly unified endorsement of a preferred set of methods of inquiry.

This should assuage the fear that the above has detrimental effects for normative epistemology. Which, of course, is not to say that the epistemic expressivist is home free. While the above outlines a solid and promising starting point for further investigation, providing anything approximating a fully comprehensive defense of epistemic expressivism (even of a moderate kind) is beyond the scope of the present paper. For example, partly because many of the objections in question already have been explored in detail by others, I have left unaddressed any objections to expressivism in general, such as that it is unable to handle embedded constructions or account for the intuition that normative discourse is truth-apt. ${ }^{22}$ I have also ignored some prominent arguments that have been leveraged against specifically epistemic versions of expressivism, including that such an expressivism is

\footnotetext{
$\overline{22}$ See Ridge (2006) for a fairly recent, comprehensive discussion.
} 
dialectically incoherent. ${ }^{23}$ However, in this case, too, the objections in question have already been addressed by several recent contributors to the debate. ${ }^{24}$ It is as a complement to this broad defensive front that the present paper instead has attempted to strike a constructive note by demonstrating the merits of an epistemically expressivist framework in explaining important epistemological data, including data in epistemological axiology. ${ }^{25}$

That said, the fact that a series of arguments has failed to undermine or otherwise discredit moderate epistemic expressivism, of course, does not establish that such expressivism is true-not even given its ability to explain a significant but puzzling axiological datum, i.e., that there are at least two viable yet mutually incompatible answers that one may give to the question of what is of non-instrumental epistemic value. But here, as in general, an ability to not only explain significant data but also withstand strong counterarguments counts for something, and indicates that moderate epistemic expressivism is a theory to be reckoned with in contexts where we wish to explain the grounds of epistemic value in a manner that will not automatically beg the question one way or the other.

Acknowledgments Many thanks to J. C. Bjerring, Jeff Dunn, Mikkel Gerken, Alvin Goldman, Nikolaj Jang Lee Linding Pedersen, Klemens Kappel, Hilary Kornblith, Michael Lynch, Emil Møller, Jonathan Vogel, Åsa Wikforss, and an anonymous reviewer for this journal for valuable comments on earlier drafts of this paper. Research underlying the present paper was conducted with generous support from the Wenner-Gren Foundation.

\section{References}

Alston, W. (2005). Beyond "justification": Dimensions of epistemic evaluation. Ithaca: Cornell University Press.

Ayer, A. J. (1952). Language, truth and logic. New York: Dover Publications.

Blackburn, S. (1993). Essays in quasi-realism. New York: Oxford University Press.

Blackburn, S. (1998). Ruling passions: A theory of practical reasoning. Oxford: Oxford University Press.

Boghossian, P. (2006). Fear of knowledge: Against relativism and constructivism. Oxford: Oxford University Press.

BonJour, L. (1985). The structure of empirical knowledge. Cambridge: Harvard University Press.

Carter, J. A., \& Chrisman, M. (2011). Is epistemic expressivism incompatible with inquiry? Philosophical Studies. doi:10.1007/s11098-011-9710-9.

Chisholm, R. (1977). Theory of knowledge (2nd ed.). Englewood Cliffs: Prentice-Hall.

Chisholm, R. (1991). Firth and the ethics of belief. Philosophy and Phenomenological Research, 51(1), 119-128.

Chrisman, M. (2007). From epistemic contextualism to epistemic expressivism. Philosophical Studies, $135,225-254$.

Clifford, W. K. (1866). The ethics of belief. In L. Stephen \& F. Pollock (Eds.), Lectures and essays by the late William Kingdon Clifford (2nd ed., pp. 339-363). New York: Macmillan and Co.

Conee, E., \& Feldman, R. (2008). Evidence. In Q. Smith (Ed.), Epistemology: New essays (pp. 83-104). Oxford: Oxford University Press.

Cuneo, T. (2007). The normative web: An argument for moral realism. Oxford: Oxford University Press.

\footnotetext{
${ }^{23}$ See Kvanvig (2003) and Cuneo (2007) for two variants on this objection.

24 See, e.g., Carter and Chrisman (2011).

25 See also Chrisman (2007) on how epistemic expressivism can retain the virtues while shedding the characteristic vices of contextualism, and Kappel (2010) on accounting for the value of knowledge in expressivist terms.
} 
David, M. (2001). Truth as the epistemic goal. In M. Steup (Ed.), Knowledge, truth, and duty (pp. 151-169). New York: Oxford University Press.

DePaul, M. (1993). Balance and refinement: Beyond coherentism in moral inquiry. New York: Routledge.

Feldman, R. (1988). Epistemic obligations. Philosophical Perspectives, 2, 235-356.

Feldman, R. (2002). Epistemological duties. In P. Moser (Ed.), The Oxford handbook of epistemology (pp. 361-384). Oxford: Oxford University Press.

Feldman, R. (2003). Chisholm's internalism and its consequences. Metaphilosophy, 43(5), 603-620.

Feldman, R., \& Conee, E. (1985). Evidentialism. Philosophical Studies, 48, 15-34.

Field, H. (2001). Truth in the absence of fact. Oxford: Oxford University Press.

Field, H. (2009). Epistemology without metaphysics. Philosophical Studies, 143, 249-290.

Gibbard, A. (1990). Wise choices, apt feelings. Cambridge: Harvard University Press.

Goldman, A. (1999). Knowledge in a social world. Oxford: Oxford University Press.

Goldman, A. (2011). Toward a synthesis of reliabilism and evidentialism? Or: Evidentialism's problems, reliabilism's rescue package. In T. Dougherty (Ed.), Evidentialism and its discontents. Oxford: Oxford University Press.

Haack, S. (1993). Evidence and inquiry: Towards reconstruction in epistemology. Oxford: Basil Blackwell.

Haack, S. (2001). 'The Ethics of Belief' reconsidered. In M. Steup (Ed.), Knowledge, truth, and duty (pp. 21-33). Oxford: Oxford University Press.

Kappel, K. (2010). Expressivism about knowledge and the value of knowledge. Acta Analytica, 25(2), 175-194.

Kvanvig, J. (2003). The value of knowledge and the pursuit of understanding. New York: Cambridge University Press.

Kvanvig, J. (2005). Truth is not the primary epistemic goal. In M. Steup \& E. Sosa (Eds.), Contemporary debates in epistemology (pp. 285-296). Cambridge: Blackwell.

Lynch, M. (2004). True to life: Why truth matters. Cambridge: The MIT Press.

Lynch, M. (2009a). The values of truth and the truth of values. In A. Haddock, A. Millar, \& D. Pritchard (Eds.), Epistemic value (pp. 225-242). Oxford: Oxford University Press.

Lynch, M. (2009b). Truth, value and epistemic expressivism. Philosophy and Phenomenological Research, 79(1), 76-97.

Olsson, E. J. (2005). The impossibility of coherence. Erkenntnis, 63, 387-412.

Pritchard, D. (2010). Knowledge and understanding. In D. Pritchard, A. Millar, \& A. Haddock (Eds.), The nature and value of knowledge: Three investigations. Oxford: Oxford University Press.

Ridge, M. (2006). Ecumenical expressivism: Finessing Frege. Ethics, 116, 302-336.

Sosa, E. (2003). The place of truth in epistemology. In M. DePaul \& L. Zagzebski (Eds.), Intellectual virtue: Perspectives from ethics and epistemology. Oxford: Oxford University Press.

Swinburne, R. (1999). Providence and the problem of evil. Oxford: Oxford University Press.

Wolterstorff, N. (2005). Obligation, entitlement, and rationality. In M. Steup \& E. Sosa (Eds.), Contemporary debates in epistemology (pp. 326-338). Cambridge: Blackwell Publishing.

Zagzebski, L. (2003). The search for the source of epistemic good. Metaphilosophy, 34, 12-28. 